\title{
LOS CONFLICTOS ENTRE LA CABALLERÍA LOCAL Y EL EPISCOPADO ZAMORANO: VILLAMOR DE LOS ESCUDEROS DURANTE EL SIGLO XIII
}

\author{
Carla Cimino ${ }^{1}$
}

\begin{abstract}
RESUMEN
El presente trabajo tiene como objetivo considerar la importancia que adquiere el marco señorial en el éxito o fracaso de la caballería local en la vía hacia la diferenciación social. Especialmente nos interesa analizar el caso de las comunidades de la Extremadura histórica que no permanecen en el realengo concejil, puntualmente aquellas que pasan a la órbita del señorío del obispo de Zamora. Pretendemos demostrar que, a diferencia de lo que sucede en el realengo, estos sectores de caballería, lejos de desempeñar un rol positivo en relación a la consolidación del señorío episcopal, se erigen en competidores directos de la instancia señorial en el proceso de feudalización. En este sentido será central entender el problema considerando las relaciones de fuerza que, en un contexto determinado, enfrentaron a la caballería y al señor episcopal. A tal fin emplearemos exclusivamente documentación del Archivo Catedralicio de Zamora a fin de ilustrar, en primer lugar, qué factores sociales inclinan al conflicto entre los señores eclesiásticos y la caballería local; y, en segundo lugar, qué formas adquirió la disputa en el caso concreto de Villamor de los Escuderos, comunidad cercana al concejo de Toro.
\end{abstract}

Palabras Clave: Caballería, Realengo, Abadengo, Señorío episcopal, Villamor de los Escuderos, Zamora.

\section{ABSTRACT}

This study aims to consider the importance of signorial frame in the success or failure of the local chivalry on the road to social differentiation. We are especially interested in communities that do not stay inside realengo, specifically in the case of those entering in the lordship of the bishop of Zamora. We intend to demonstrate that, unlike what happens in the realengo, chivalry, far from playing a positive role in the consolidation of the episcopal

Fecha de recepción: 13 de octubre de 2009. Fecha de aceptación: 29 de diciembre de 2009

1 CEHSE (IdIHCS). Universidad Nacional de La Plata. Email: carlacimino@ hotmail.com. 
manor, set themselves up as direct competitors of the lord in the process of feudalisation. In this respect it will be central to understand the problem considering the streght relations that opposed the cavalry to the bishop. To this end we will use only documentation from the Zamora Cathedral Archive to illustrate, first, how social matters lead to conflict between the ecclesiastical lords and local cavalry, and, secondly, the shape of the dispute in the case of Villamor de los Escuderos, a community near Toro.

Key Words: Chivalry, Realengo, Abadengo, Episcopal lordship, Villamor de los Escuderos, Zamora.

\section{INTRODUCCIÓN}

El problema del surgimiento de la caballería de los concejos de la Extremadura histórica ha generado amplios debates a través de décadas de historiografía especializada. Mucho se ha dicho, sobre todo, de las vías de consolidación de la fortuna de dicho sector al cual se reconoce un origen campesino. Varios historiadores ${ }^{2}$ han constatado, al analizar la documentación de los concejos realengos, la presencia de la caballería villana en el escalón inferior de la estructura de poder feudal. Más allá de las diferencias considerables en las caracterizaciones que proponen dichos autores, constituye un lugar común el afirmar que el ejercicio de funciones militares y políticas habría favorecido la formación de un grupo oligárquico consolidado hacia mediados del siglo XIII. Podríamos afirmar, sin temor a violentar sus tesis, que al mismo tiempo que se consolida el aparato político y tributario, cristalizan estas elites locales estrechamente vinculadas al ejercicio del poder.

El presente trabajo, sin embargo, tiene como objetivo considerar un aspecto menos estudiado: qué sucede con este sector de caballeros villanos en el caso de las comunidades de la Extremadura histórica que no permanecen en el realengo concejil, puntualmente en el caso de aquellas que pasan a la órbita del señorío del obispo de Zamora. Pretendemos ilustrar la importancia que adquiere el marco señorial en el éxito o fracaso de este sector en la vía hacia la diferenciación social. Partimos de la hipótesis de que, a diferencia de lo que sucede en el realengo concejil, estos sectores de caballería, lejos de desempeñar un rol positivo en relación a la consolidación del señorío episcopal, se erigen en competidores directos (o al menos en escollos) del señor en el camino hacia el control de hombres y tierras, es decir, en el proceso de feudalización. En este sentido será central entender el problema considerando las relaciones de fuerza que, en un contexto determinado, enfrentaron a la caballería y al señor episcopal. A tal fin emplearemos exclusivamente

2 BARRIOS GARCÍA, A.: Estructuras agrarias y de poder en Castilla: El ejemplo de Ávila (1085-1320), Salamanca, 1983-1984; VILLAR GARCÍA, L.: La Extremadura castellano-leonesa. Guerreros, clérigos y campesinos (711-1252), Junta de Castilla y León, 1986; MONSALVO ANTÓN, J. M.: El sistema político concejil. El ejemplo del señorío medieval de Alba de Tormes y su concejo de villa y tierra, Salamanca, 1988; MARTÍNEZ SOPENA, P.: La Tierra de Campos Occidental. Poblamiento, poder y comunidad del siglo X al XIII, Valladolid, 1985; MARTÍNEZ MORO, J.: La tierra en la comunidad de Segovia. Un proyecto señorial urbano (1088-1500), Valladolid, 1985; entre otros. 
documentación del Archivo Catedralicio de Zamora ${ }^{3}$ a fin de ilustrar, en primer lugar, qué factores sociales inclinaron al conflicto a los señores eclesiásticos y la caballería local; y, en segundo lugar, qué formas adquirió la disputa en el caso concreto de Villamor de los Escuderos, comunidad cercana al concejo de Toro.

\section{ALGUNAS CONSIDERACIONES A PARTIR DE LA HISTORIOGRAFÍA}

La naturaleza feudal de los concejos de la Extremadura castellano-leonesa halló en la tesis de Ángel Barrios García ${ }^{4}$ su formulación más sólida. Según el autor, durante el avance repoblador, la clase señorial obtuvo derechos eminentes sobre los territorios que sustentaron la extracción del excedente en base a la delimitación jurisdiccional cuando se establecieron los mecanismos necesarios para esto ${ }^{5}$ : alfoces, diócesis, y, posteriormente, comunidades de villa y tierra. El concepto de "bloque social hegemónico" fue determinante al intentar dar cuenta de la identidad básica entre los dos sectores sociales dominantes, la caballería y el clero capitular, comparables en tanto que detractores del excedente campesino ${ }^{6}$. La renta se realizaba desde el siglo XII a través de los concejos y de los cabildos catedralicios: los campesinos eran explotados sobre esta doble base por los sectores mencionados. El trabajo de Barrios García vino a completar la revisión historiográfica sobre las visiones clásicas de la "excepcionalidad castellana” e inspiró investigaciones posteriores sobre el tema y el área ${ }^{7}$. Si bien su propuesta tuvo algunos $\operatorname{críticos}^{8}$ y fue cuestionada, sobre todo, la idea de que la caballería pueda asimilarse a la nobleza del norte peninsular continúa pendiente, desde nuestro punto de vista, la revisión del punto anteriormente explicitado: ¿es lícito asimilar socialmente a los dos sectores que Barrios García integra en el bloque social dominante ${ }^{9}$ ? ¿Es correcto suponer que, más allá de

3 SÁNCHEZ RODRÍGUEZ, M.: Tumbo Blanco de Zamora, Salamanca, 1985; y Fueros y posturas de Zamora (Tumbos Blanco y Negro), Salamanca, 1987. Citados en adelante como "TBZ" y "Fueros..." respectivamente.

4 BARRIOS GARCÍA, A.: Op. cit.

5 Ibíd., p. 215 y ss.

6 "Casi simultáneamente, porque colaboraban en la guerra y desempeñaban una función esencial en sociedades rurales donde predomina el pensamiento mágico, como la religiosa, los laicos y eclesiásticos que componían el bloque superior obtuvieron de la monarquía la exención impositiva. (...) En el polo opuesto, en el otro extremo del ordenamiento social, seguía estando la mayoría de la población. (...) En efecto, los agricultores, los artesanos y pequeños comerciantes urbanos conformaban el bloque social dependiente y subordinado." Ibid., pp. 209-210 (La cursiva es del autor).

7 VILLAR GARCÍA, L. M.: Op. cit.

8 Por nombrar sólo algunos: ASTARITA, C: "Estructura social del concejo primitivo de la Extremadura castellano-leonesa. Problemas y controversias.", Anales de Historia Antigua y Medieval, vol. 26, 1993. MONSALVO ANTÓN, J. M.: "Transformaciones sociales y relaciones de poder en los concejos de frontera, siglos XIXIII. Aldeanos, vecinos y caballeros ante las instituciones municipales.” En: Relaciones de poder, de producción y parentesco en la Edad Media y Moderna. Reyna Pastor (Comp.), CSIC, Madrid, 1990.

9 “...la caballería villana y el episcopado estaban plenamente identificados, incluso a nivel familiar. Con la excepción de los dos obispos dominicos, quienes detentaban el máximo poder político laico a escala comarcal no parece que perdieran en ningún momento el control absoluto de la mayor autoridad eclesiástica. Sin duda, se aseguraba así la participación en el poder por casi todos los miembros de un mismo linaje, a la vez que se completaba la hegemonía política y la dominación social por la propia familia caballeresca.” BARRIOS GARCÍA, A.: Op. Cit., Vol. II, p. 189. 
"conflictos ocasionales"10, los intereses de ambos sectores son uniformes? Especialmente, ¿son concurrentes sus formas de explotación del patrimonio? No es infrecuente hallar en la documentación zamorana referencias a conflictos protagonizados por la caballería local y el obispo hacia el siglo XIII. Pero más allá de dicha impresión corresponde revisar lo que sabemos del surgimiento y las pautas de reproducción de ambos sectores.

La caballería villana posee un origen campesino, este es un punto de consenso generalizado entre los historiadores. Sin embargo, no existe acuerdo ni al momento de explicar la vía hacia la plena conformación del sector (con los privilegios de mediados del siglo XIII), ni en relación a su caracterización durante la etapa de madurez del mismo. Existen por lo menos dos propuestas en cuanto a su caracterización sociológica ${ }^{11}$, y otras tantas en relación a su función o inserción en la estructura de poder feudal ${ }^{12}$. Pero ¿qué podemos decir sobre la base que sustenta los caballeros a mediados del siglo XIII? Sabemos que, en algún punto de su evolución, el sector privilegió la ganadería por sobre las tareas agrícolas; esto llevó a requerir el acceso a los pastos de los términos concejiles. Esa especialización, de todos modos, no parece ser anterior al contexto que nos interesa. De todos modos podemos conocer, por medio de la comparación, un poco más sobre el problema de la evolución de la exención de la caballería de Toro en la época que nos interesa, cuestión central en relación al problema de la conformación del grupo. La elección no es fortuita ya que Villamor, caso que analizaremos en detalle más adelante, se halla en los términos de dicho concejo y que volveremos a mencionar a la caballería toresana al estudiar esta comunidad. Poseemos tres documentos que nos permiten evaluar de manera convincente la situación de la caballería durante el siglo XIII: son el fuero regio de 1222 y las cartas de privilegios de 1283 y $1301^{13}$.

Del primer documento se desprende que, en el primer cuarto del siglo XIII, el concejo se encuentra segmentado en distintos estratos: los caballeros, los pecheros y los yugueros. Los primeros poseen la capacidad de excusar determinado número de dependientes, según

10 Ibid., pp. 213 y 215.

11 Algunos historiadores han considerado que la caballería debe asimilarse a la nobleza feudal ya que detenta un señorío, aunque sea como colectivo. Por ejemplo, MíNGUEZ FERNÁNDEZ, J. M.: "Feudalismo y concejos. Aproximación metodológica al análisis de las relaciones sociales en los concejos medievales castellano-leoneses", En: En la España Medieval, III, Madrid, 1982. Por otro lado, algunos autores se inclinan por la caracterización del caballero como verdadero "propietario privado" (exento) y cuya reproducción, se sustenta en la producción de bienes destinados al mercado. Ver, ASTARITA, C: "Caracterización económica de los caballeros villanos de la Extremadura castellano-leonesa (siglos XII-XV)", Anales de Historia Antigua y Medieval, vol. 27, 1994.

12 Siguiendo la caracterización propuesta, Minguez Fernández entiende que los caballeros perciben rentas del campesinado a través del concejo, instancia que monopolizan. En cambio, Monsalvo Antón no comparte esta idea pues entiende al concejo como aparato político complejo en el cual confluyen y se condensan diferentes intereses; y, si bien los caballeros pueden aprovechar sus mecanismos políticos para orientarlos a su favor, de ningún modo monopolizan el espacio, el cual no expresa, de forma exclusiva, sus intereses como estamento. Por otro lado, para Astarita los caballeros desempeñan una función central en el sistema político feudal al reproducir como colectivo el señorío realengo; esta función les permite obtener ventajas comparativas respecto a otros productores rurales en tanto que gozan de exenciones tributarias. Ver textos citados más arriba.

13 Docs. 44, 73 y 80, respectivamente; en: RODRÍGUEZ FERNÁNDEZ, J.: Los fueros locales de la provincia de Zamora. Junta de Castilla y León. 1990. 
su contribución a la hueste ${ }^{14}$; dicha capacidad se ve limitada en relación a los vecinos con mayor valía.

De todos modos, pueden identificarse ya procesos de pauperización campesina; el fuero reconoce distintas categorías dentro del grupo de los yugueros que se relacionan con la calidad y cantidad de bienes que conservan ${ }^{15}$. Los que poseen casa poblada y heredades de pan y vino no pueden eximirse de tributar; presumiblemente el empleo como yugueros signifique, en estos casos, un complemento del trabajo en la propia heredad. En cambio, sí se hallan exentos los yugueros a cuarto - que es la forma más frecuente de la relación de yuguería en los fueros extensos - los que, probablemente, se encuentren más desposeídos que los primeros ya que se contratan en peores condiciones. El fuero contempla la existencia de relaciones especiales entre los "solariegos"16 y su "dominus" ${ }^{17}$; no parece exagerado vincularlas a las relaciones agrarias entre sectores enriquecidos y empobrecidos de la comunidad.

A fines de siglo se completa el panorama. Los privilegios de 1283 y 1301 constatan el grado en que los caballeros de Toro han progresado en su diferenciación del resto de la comunidad: han conseguido el reconocimiento de su exención en la tributación ${ }^{18}$. Nada se menciona en dichos documentos sobre los excusados de caballero, indicio, desde nuestro punto de vista, del afianzamiento local de esta capacidad sobre la cual ya no es necesario legislar.

En definitiva, con el transcurso del siglo la caballería toresina logra tanto eximirse de la tributación, como afianzar la capacidad de excusar dependientes. Podemos inferir de la documentación considerada que los excusados de caballeros son generalmente los encar-

14 RODRÍGUEZ FERnÁNDEZ, J.: Op. Cit. Doc. 44: Fuero de Toro 1222, Tít. 6: "Homo qui levaverit recundam et caballum in hostem liberet quatuor excusatos. Qui levaverit signam liberet duodecim excusatos, et toti illi qui excusatos liveraverit non liberent excusatos de trecentis morabetinis."

15 Ibíd. Títs. 3: "Iugarius qui casam suam populatam tenuerit cum pane et vino de sua hereditate, pectet si habuerit per quod." y 5: "Iugarius medanarius pectet. Iugarius non pectet pro ortis nec pro vineis. Iugarius de quarto non pectet..."

16 En este título del fuero la palabra "solariego" probablemente se emplee por contraposición a la de "heredero" para expresar la diferencia estatutaria entre unos y otros, y no para dar cuenta de una relación vasallática.

17 Ibíd. Tít. 8: "Solaregus qui intraverit sub domino cum balia de decem morabitinis in hereditate aut cum viginti in mobili pectet. Alter solaregus non pectet."

18 RODRÍGUEZ FERNÁNDEZ, J.: Op. Cit. Doc. 73: Concesión de privilegios a Toro de 1283, Títs. 6: "Otrosi, vos do et vos otorgo, que todo hombre que toviere caballo que valga veinte morbetinos de la bona moneda, ó que los cueste, et que sea del primero diente ó de mais, por la fiesta de San Martino et por la Pascua de la Resurreccion, que non pechen en ninguna cosa." у 7: "Et porque habedes esto en privilegio, et non vos fue guardado senon en la martiniega, dovos et otorgovos que tales como estos que tuvieron los cavallos, cuemo manda el previlegio, que sean excusados de todo pecho pora siempre jamas." Y Doc 80: Concesión de privilagios a Toro de 1301, Tít. 1: “A lo que me pidieron que quisiese que los cogedores que cogen los servicios é los otros pechos por mi en la villa que les guardasen los previlegios que han de los reyes, en los quales se contiene que todos aquellos que tovieren caballos é armas por la festa de San Martino, é por la pasqua de la resurreccion, que vala veinte maravedis de la buena moneda, é que les coste que non pechen en ningun pecho, tengo por bien que los privilegios que han en esta razon que les sean guardados: porque tengo por bien que los que tovieren caballos é armas de suyo, que los muestren cada anno al juiz é al notario de la villa por el san Martin, é por la pasqua de resurreccion; é el notario que los ponga en el padron, porque los mis cogedores que hobieren de recabdar los mis pechos sepan quales son é quantos los que mostraren caballos é armas; é los que asi mostraren é fueren puestos en el padron, como dicho es, que sean escusados de los pechos, segun manda el previlegio." 
gados de poner en valor las tierras del sector. Hasta aquí comprobamos que en el concejo más cercano a nuestro caso de estudio la evolución social se corresponde con la de los grandes concejos del área con lo cual no nos distanciamos en esencia de lo sostenido por los historiadores mencionados ${ }^{19}$.

Ahora bien, resta considerar en qué medida este panorama podría corresponderse con la formación y explotación del patrimonio episcopal. Poseemos algunos antecedentes historiográficos sobre el problema de la superposición de una instancia señorial eclesiástica a comunidades con presencia de caballería. Reyna Pastor para el caso de Galicia y Rosana Vassallo para el de Liébana encuentran algunas familias que poseen cierto control de recursos económicos y políticos fundamentales en la sociedad rural antes de la irrupción del señor eclesiástico ${ }^{20}$. Las autoras no concuerdan, no obstante, en relación a las consecuencias que derivan de este contacto entre instancias que se perfilan como competidoras en cuanto al control de los recursos. Mientras que para Reyna Pastor las relaciones entre ambos actores conducen a la integración de los "sectores dominantes locales" en las redes de relaciones del monasterio, para Rosana Vassallo puede constatarse una estrategia del cenobio tendiente a desestructurar las bases de poder que sustentaban la jerarquía de los mismos. Esta estrategia consta en la formación de vínculos específicos con sectores intermedios de la comunidad cuyo estatus preferencial depende de la relación con el señor.

Sin pretender extrapolar las conclusiones de las autoras mencionadas a la Extremadura zamorana, hallamos aquí un precedente para considerar el problema del contacto entre comunidades con presencia de caballería y señores eclesiásticos. Creemos que en el caso de comunidades campesinas con desarrollo de caballería en áreas de realengo, si bien ciertamente existen obligaciones militares y tributarias, éstas no niegan la autonomía relativa de que disfrutan los campesinos-guerreros. En cambio, cuando hablamos de comunidades sujetas a señorío eclesiástico, dicha posibilidad está vedada, pues reyes y condes exceptúan de obligaciones militares a monasterios o catedrales y sus vasallos. Además dichos señores pretenden incidir en mayor medida en las condiciones internas de la comunidad y no favorecen la proliferación de sectores exentos. Por esta razón intentarán bloquear los procesos de acumulación, en el caso de que existan. Frente a los caballeros villanos, por ejemplo, el señor recurrirá a la exención generalizada de tributos militares (suprimiendo así una de las bases de su posición de privilegio) y al intento de imponer rentas de manera

19 Ver supra, nota 1.

20 VASSALLO, R.: Estructura y dinámica del dominio de Santo Toribio de Liébana (siglos XIII-XVI), Salamanca, 2003. p 32 y ss. Donde atestigua la existencia de "fijosdalgos" en las comunidades lebaniegas del siglo XIII. Reyna Pastor los caracteriza de la siguiente manera, para la Galicia del siglo XIII: "Muchos de los miembros de estos grupos dominantes aparecen calificados socialmente en la documentación, como domini o dominae, o destacan en el entorno local al ejercer funciones de tipo político, generalmente milites, armigeri - caballeros y escuederos - a cuenta del rey o de miembros de la alta nobleza gallega, a veces a cuenta de otros pequeños nobles locales, incluso del abad de Oseira, pero en su mayoría sin vinculación explícita a organizaciones mayores. Se trata de grupos que no siempre tienen signos externos que denoten su preeminencia social (algunos no son domini, o no siempre ejercen funciones de milites, etc.), pero cuyas redes de relaciones sociales, hiladas minuciosamente, nos hacen ver que se trata de gente importante que pueden negociar con ventaja con el monasterio, ejercer presión sobre él y limitar su capacidad de maniobra." PASTOR, R. et al: Transacciones sin mercado: instituciones, propiedad y redes sociales en la Galicia monástica. 1200 - 1300, CSIC, Madrid, 1999. p. 142. 
uniforme. Resta considerar, a la luz del caso de Villamor de los Escuderos, qué aspectos de los mencionados permiten abordar el problema del contacto entre señorío episcopal y caballería local.

\section{LA CONSIDERACIÓN DE LAS FUENTES ZAMORANAS}

Debemos comenzar por situar geográfica y cronológicamente la comunidad que será objeto de nuestro estudio de caso; se trata de Villamor de los Escuderos, villa situada en el sur de la actual provincia de Zamora. Los primeros documentos existentes datan de mediados del siglo XIII, época en la que el obispo Suero comienza a interesarse en la villa; podemos, no obstante, reconstruir la situación inmediatamente anterior — principios del siglo XIII - mediante una lectura atenta de los mismos.

Villamor había sido cedida por Alfonso VII ${ }^{21}$ a un matrimonio favorecido cuyos descendientes constituirán, con el transcurso del tiempo, la familia principal de la comunidad, los Pelaiz. Su posición se sustenta, hacia principios del siglo XIII, tanto en el ejercicio de la caballería ${ }^{22}$, como en la concentración de propiedades en el lugar ${ }^{23}$. En este sentido, no constituye novedad alguna señalar que el ejercicio de funciones militares especializadas conlleva la posibilidad de acumulación de riquezas, dando lugar incluso a procesos de diferenciación social ${ }^{24}$ que la transforman en un estamento con características particulares. Dicho lugar de preeminencia aparece, de todos modos, cuestionado inicialmente por los reclamos del concejo de Toro, que se atribuye derechos sobre tierras de esta aldea ${ }^{25}$ (aparentemente vendidas a algunos caballeros toresanos en 1223). Ambas caballerías, la de raigambre local y la toresana, explotan el trabajo de vasallos, hortelanos y yugueros ${ }^{26}$

21 TBZ 361, s/f: "Renebranza de lo que fallo el obispo en Fernant Pelayz et en otros omnes bonos de Villamor de cómo fura pobrada pobrola on Paley Vilidez et sua muyer Mayor Echez et dioya el emperador en donation..."

22 Por citar sólo dos casos, en TBZ 343 de 1259 se menciona a Lope Garcia, escudero de Villamor y en TBZ 383 (s/f) se menciona a Munio Pelaiz caballero de la misma aldea. Dicho personaje es el miembro principal de la familia Pelaiz en la época que consideramos en este trabajo.

23 TBZ 373, 1270: Se divide una dehesa, acuden: “...de partes del obispo Alvar Gonzalvez et Gonzalvo Garcia et Gonzalvo Matheos e de parte de los herederos Gil Rodriguez [por otros documentos sabemos que es caballero de Toro] et Pelay Perez [idem] et fillos de Fernant Pelayz [caballero de Villamor] et fillos de Munio Pellayz [caballero de Villamor y hermano del anterior] por si et por donna Orraca [esposa de Munio Pellayz] $e$ los yernos de Mayor Pellaez [posiblemente hermana del anterior]...” Similar panorama aparece de la relación de los herederos que tienen participación de las dehesas de Villamor efectuada en 1271.

24 Entendemos por "procesos de diferenciación social" aquella evolución que permite que un sector se escinda de su clase de origen. En el caso presente, y partiendo de la clase campesina, el proceso engloba no sólo a la caballería, sino también a los representantes señoriales a nivel local. Ambos sectores son asimilables en tanto que se separarán de la clase campesina a través de la exención tributaria.

25 TBZ 347, 1223, documento de la venta mencionada donde se hace mención a los derechos de Toro de recoger leña en los bosques de Villamor.

26 Entre otros documentos, en TBZ 353 se mencionan dos vasallos de Gil Rodríguez; en 374, de 1271, se alude a los vasallos de Pelayo Perez y su hijo; y en 376, de 1271, aparecen mencionados los vasallos de Ruy Perez y su mujer (hija de Munio Pelaiz). Vale la pena citar mejor un documento más explícito en este sentido, TBZ 382. s/f: “Estos son los vassallos que ha el obispo en Villamor: (...) Yuanuellos el ortolano (...), don Thome iuguero de Gil Rodriguez (...), don Iohannes ortolano vieyo.” 
que cultivan sus tierras, las cuales se hallan en su mayoría dispersas ${ }^{27}$. Es decir, nos encontramos frente a un sector con cierto grado de consolidación: no sólo aparecen ejerciendo funciones especiales, sino que además comienzan a subordinar a algunos de sus vecinos más pobres y a alejarse en cierta medida del trabajo agrario. Como puede comprobarse, en Villamor parece existir una caballería consolidada sobre la base del control de la tierra.

En este contexto interviene el señor episcopal que, al no poseer el señorío de la villa, comienza a acumular tierras por medio de sucesivas compras. Dicho proceder encontraría un freno dado por ciertas pautas de tenencia de la tierra: los miembros de la familia Pelaiz poseen bienes tanto de manera individual como a título colectivo ${ }^{28}$. Este es el caso de las tierras de las dehesas, que (antes de su deslinde en 1270-71) permanecían indivisas ${ }^{29}$. Tales características del disfrute de la propiedad entre los miembros de la familia principal pueden haber determinado que, en una primera instancia, el obispo se orientase a comprar los bienes de los caballeros de Toro y de los propietarios eclesiásticos del lugar ${ }^{30}$.

Dichas compras generan descontento entre los caballeros toresanos quienes instan a su concejo a entablar un pleito que se desarrolla entre 1262 y $1265^{31}$. La disputa parece girar en torno a la creciente importancia que adquiere el obispo en la comunidad y al antagonismo existente entre las formas de aprovechamiento de los recursos de uno y otro sector. El avance del obispo como terrateniente local se halla en conflicto con las necesidades del concejo de Toro de aprovechar los pastos y bosques de esta aldea. Algunos documentos adicionales nos permiten deducir que los primeros caballeros en vender o permutar bienes reciben a cambio rentas vitalicias del episcopado o exenciones ${ }^{32}$. Tales ventas redundan entonces en la pérdida de los derechos del concejo de Toro en el lugar, razón por la cual el propio concejo afronta el pleito. De cualquier manera, se comprueba

27 Documentos en los que se enumeran los bienes de los herederos de Villamor: TBZ 338, 353, 355, 371, $372,378,379,380,384$ y 386 . En todos se constata que las tierras de los herederos se hallaban dispersas pues se mencionan los lugares en los que se hallaban. Ver infra notas siguientes.

28 Por tomar sólo un caso TBZ 386, s/f: bienes de don Lorenzo y su mujer en Villamor: “...otra tierra que ha de partir con sos hermanos al carril, otrossi que ha de partir tierras en II lugares con sos hermanos, otrossi que ha de partir en II lugares deffessa con sos hermanos...”

29 TBZ 350, 1271: "Estas son las deffessas de Villamor et los herederos delas: en la deffesa de la Silva el obispo ha ela mitad et de la otra meatad que fica ha Gil Rodriguez el quarto et la muyer de Munio Pellaez et sos antenados han el otro quarto et deste mismo quarto ha el obispo un quinnon que compro de Pedro Fernandez, et de sua muyer et los otros dos quartos son de Diego Remondez."

30 En 1257 compra los bienes de Sancho Alfonso, TBZ 362; en 1259 compra los bienes de Álvaro Domingo, TBZ 369, y de Pelayo Díaz, TBZ 343; los tres son caballeros de Toro. Al mismo tiempo - o quizás antes Suero compraba las heredades de San Miguel del Monte, de los hermanos del Hospital y de Roncesvalles, TBZ 342 , s/f.

31 TBZ 344, 1262: “...et los personeros del conceyo [de Toro] querelaron que el obispo sen raçon et sen derecho comprara et tenia la mayor parte de Villamor que era suya del conceyo de Toro...”; 345, 1262: “...et los personeros del obispo et dellos herederos querellaron que el conceyo de Toro les entrava sus montes et gelos cortavan et pasçian sus hervas en la villa et en lo termino de Villamor et los fazian hy otros dannos et otros tuertos muchos...” у 356, 1265: “...el obispo de Zamora se nos envio querellar de vos quel non queredes guardar las sentencias que nos diemos entrel et vos sobre Villa maor et so termino et que le passades contra ellos cortandole los montes et montandole en los sus ganados ..."

32 Pelayo Pérez y Ruy Pelaez, caballeros de Toro, obtienen del obispo diezmos en Pinilla a cambio de su heredad en Villamor: TBZ 374, 1271. Ruy Perez y su mujer ceden cuanto tienen en Villamor al obispo a cambio de heredades exentas en Fresno de la Ribera: TBZ 376, 1271. 
aquí lo que Ana Rodríguez López y Reyna Pastor señalaban para el caso del monasterio de Osera ${ }^{33}$ : el señor episcopal cuenta con una ventaja esencial para efectuar transacciones. Las instituciones eclesiásticas pueden realizar compraventas de tierras en diferido aún a costa de conceder beneficios de exención; los mismos tarde o temprano revertirán al señor tras la muerte de la o las generaciones beneficiadas.

Tras el conflicto con el concejo de Toro, que culmina con la victoria del obispo ${ }^{34}$, se producen las primeras compras a los miembros de la familia Pelaiz. El principal objetivo de las mismas parece ser la adquisición de derechos sobre las dehesas aún indivisas. El obispo accede a porciones de los bienes de la familia a través de la venta de uno de los miembros secundarios de la misma, Pedro Fernández ${ }^{35}$. El hecho marca un cambio de signo en las relaciones entre el obispo y los miembros de la familia Pelaiz: mientras éstos aparecen en los primeros documentos episcopales como testigos ${ }^{36} \mathrm{y}$ el conflicto con Toro los encuentra actuando en conjunto ${ }^{37}$, cuando el obispo comienza a comprar porciones de los bienes de la familia se quiebra la armonía anterior. En este sentido parece que el obispo, tras solucionar el problema de las propiedades de la caballería toresana en la aldea, se interesa en los bienes de los caballeros locales por lo cual confronta directamente con los mismos.

La virulencia de los conflictos entre el obispo de Zamora y los caballeros del área no se limita al caso de Villamor sino que, por el contrario, es un rasgo muy frecuente de la documentación zamorana. Hemos atestiguado varios ejemplos de conflictos que giran en torno al problema de la imposibilidad efectiva de percibir rentas de los bienes que el sector posee en el abadengo ${ }^{38}$. Es comprensible, entonces, que el obispo intente desinstalar a los caballeros de Toro y a los de Villamor, ya que ambos podían ofrecer resistencia efectiva a la tributación.

Por otro lado, existen otros personajes de la aldea que adquieren relevancia en esta etapa y disfrutan de una relación preferencial con el obispo. Desde el inicio de las compras a los miembros de la familia Pelaiz, los documentos atestiguan reiteradamente a los mismos personajes ejerciendo funciones para el obispo a nivel local: don Martín, el clérigo, Martín Iograr (alcalde), Pedro Fernández (merino), Gonzalo Mateos (casero) y Alfonso González (personero). Sin duda tienen, inicialmente, funciones vinculadas a la administración de los bienes recientemente adquiridos por el obispo. Posteriormente (tras la instalación de campesinos vasallos del obispo) desempeñarán todos los cargos vinculados al ejercicio del poder feudal. El caso más notable es el del mencionado Pedro Fernández, yerno del

33 RODRÍGUEZ LÓPEZ, A. y PASTOR, R.: "Reciprocidades, intercambio y jerarquía en las comunidades medievales." En: Hispania, LX / 1, N²04. 2000. pp. 71 y ss.

34 Podemos confiar en el relato del propio Suero de Zamora: TBZ 400, s/f: “...et liberavi et exemi Vilam Maiorem a iurisditione concilii de Tauro per sententiam regis (...) unde ut prosequere commode et utiliter causam de Venialvo et de Villa Mayor et de Morales que loca concilium de Tauro velabat occupare in periudicium et dapnum zamorensis ecclesie venditi et destrruxi hereditatem bonam quam habebam in Algarve..."

35 TBZ 355, s/f.

36 Por tomar un ejemplo, en una compra que el obispo efectuaba en 1260 a un caballero de Toro, aparecían entre los testigos Munio Pelaiz y su sobrino, don Diego. TBZ 367. También figura Munio en TBZ 363, 1259.

37 Ver supra nota 31, especialmente doc 345.

38 CIMINO, C.: Diferenciación social campesina y señorío episcopal. Zamora, siglos XI - XIII. UNLP. 2009 . 
personaje más importante de la villa, que se transforma en merino luego de vender sus bienes al obispo. De su posición subordinada en la familia Pelaiz, Pedro Fernández logra acceder a la exención y a cargos de poder a nivel local a través de la alianza con el señor ${ }^{39}$. Además del beneficio de la exención, el ejercicio de las funciones de merino o juez supone la posibilidad de disfrutar de parte de las caloñas. Como constituye una fuente concreta de beneficios materiales, la designación de representantes señoriales aparece como una herramienta eficaz en manos del señor para la construcción de alianzas estratégicas con determinados miembros de la comunidad campesina.

De esta manera pueden establecerse vínculos que anudan la dependencia. La misma dinámica que genera un sector de representantes del señor a escala local, y contribuye así a fijar la dependencia del campesinado, socava las bases sobre las que se asienta la posición de preeminencia de la elite preexistente. $\mathrm{Al}$ acceder a porciones de los bienes que la familia disfruta en mancomún, el obispo se introduce en la red de herederos. Adquiere, además, la posibilidad de presionar sobre los mismos en momentos de fragilidad del ciclo familiar. Lo anterior se comprueba considerando el caso del personaje principal de la familia Pelaiz: el obispo nunca compra los bienes de Munio Pelaiz durante su vida, son su viuda y sus herederos los que conceden finalmente la venta ${ }^{40}$.

El obispo parece acumular tierras con el objeto de poblarlas según las condiciones que se generalizan en las villas y aldeas episcopales del siglo XIII ${ }^{41}$. Así se pueden comprender tanto la razón por la que Villamor recibe fuero en una fecha tan tardía como la de 1272, como las características del mismo: los campesinos que acceden a poblar las tierras del obispo reciben beneficios ${ }^{42}$ vinculados con la necesidad señorial de contrarrestar la competencia que podrían haber supuesto otros sectores dominantes locales ${ }^{43}$. Villamor posee un fuero ventajoso en materia de tributación, pero que contempla también condiciones más arduas para el momento en que se pueble la heredad. El fuero como tributo de reconocimiento de señorío poseerá, en la documentación posterior, un nivel mínimo ${ }^{44}$ y se reintegrarán las sernas agrarias ${ }^{45}$ y el yantar fijado en especie. No obstante, es necesario

39 Este tipo de accionar señorial había sido descrito ya por Reyna Pastor y Rosana Vassallo, ambas desarrollan el tema de la vinculación entre la instancia señorial y los "sectores intermedios" en relación a la conformación de estructuras locales de poder. Ver: PASTOR, R. et al.: Op. Cit. y VASSALLO, R.: Op. Cit.

40 TBZ 383 y 384 (ambos s/f). También en el caso de otro de los herederos, don Menendo, las que se ven presionadas a vender son su viuda y su hija, TBZ 349, 1271.

41 Puede verse en: CIMINO, C.: Op. Cit.

42 Fueros... Villamor de los Escuderos, 1272, Títs 2: “Que todos aquellos que hy venieren poblar que sean escusados de peycho del dia quel poblador venier al lugar fasta quatro annos complidos.”, 3: "Et que sean quitos de roso et de nucio et de manaria." y 6 "Et mientre los pobladores poucos fueren et non podieren complir pora dar jantar den senos soldos pora jantar fasta que sean tantos que puedan complir pora dar jantar guysadamientre.".

43 Fueros... Villamor de los Escuderos, 1272, Títs 10: "Et los pobladores que en la sobredicha heredat poblaren non sean cabaneros nen solariegos mays sean herederos.”, 11: "Et ayan esse mismo fuero que han los herederos de Çamora.", 12: "Et nengun omne aya poderio sobre los se non el obispo de la devnadicha sey de Çamora." y 13: "Et se por aventura alguno de los pobladores heredar o cosa quesier vender vendala a tal home que faga morada en el lugar et que faga el fuero al obispo et que sea sou vassalo del obispo.”

44 TBZ 358, s/f: "Cada vassallo I moravedi de fuero."

45 TBZ 358, s/f: "Et façieren serna elos que ovieren bues: alcar, bimar et terciar et semrar, trilar et todos los vassallos segar.” 
ante todo imponer el señorío episcopal ${ }^{46}$ y colocar campesinos dependientes con residencia continuada en el lugar. En este sentido debe comprenderse la importancia que el fuero otorga a la permanencia en la aldea so pena de perder la tenencia ${ }^{47}$.

\section{CONCLUSIONES}

Recapitulando, con el caso analizado se ha pretendido caracterizar a la caballería aldeana para definir los presupuestos de su situación de privilegio e ilustrar, a su vez, su debilidad. Hemos podido comprobar que la caballería no se encuentra plenamente consolidada y que existen vías por las cuales es posible la penetración del poder señorial en la comunidad. Partiendo de un ejemplo concreto hemos observado el proceso que condujo, en no más de treinta años, a la entrada al señorío del obispo por una vía distinta a la de la donación regia. Si bien años atrás José Luis Martín señalaba que Villamor ingresaba al señorío por medio de estas transacciones de tierra ${ }^{48}$, nada había sido dicho sobre el microproceso de desintegración de la elite local preexistente. Hemos evidenciado una forma de accionar señorial marcada por la conformación de alianzas selectivas.

El caso ha permitido identificar satisfactoriamente a los actores sociales para ilustrar en qué medida sus relaciones dependen de la correlación de fuerzas. Mientras el obispo no tiene gran presencia en la villa su principal objetivo consiste en la disputa con el vecino concejo de Toro por el predominio sobre la misma. En la medida en que logra acaparar los bienes de los caballeros de Toro, puede ejercer mayor presión sobre los grandes herederos locales para comprar sus tierras y colocar en ellas a sus vasallos, cuyo estatus no se diferenciará del resto del campesinado del episcopado zamorano. Pero para lograr desestructurar el linaje local más importante concierta una alianza con uno de sus miembros que logra, por este medio, la exención y el disfrute de un puesto de poder a nivel local. Dicha alianza constituye la punta de lanza que contribuirá a la imposición de las condiciones sociales más favorables al señorío eclesiástico, cuyos presupuestos elementales radican en la homogeinización del estatus del campesinado y la exención de las tareas militares.

\section{BIBLIOGRAFÍA}

ASTARITA, C: "Estructura social del concejo primitivo de la Extremadura castellanoleonesa. Problemas y controversias.", Anales de Historia Antigua y Medieval, vol. 26, 1993.

ASTARITA, C: "Caracterización económica de los caballeros villanos de la Extremadura castellano-leonesa (siglos XII-XV)", Anales de Historia Antigua y Medieval, vol. 27, 1994.

46 Fueros... Villamor de los Escuderos, 1272, Tít 4: "Et cada uno de los pobladores que dey a nos et a nostros successores IIII soldos cada anno por fuero et por marteniega salvo los derechos del rey."

47 Fueros... Villamor de los Escuderos, 1272, Títs 14: "Et la casa et el heredamiento que ovier el poblador que lo aya pora fiyo et pora nieto et pora bisnieto.”, 16: “Et qual quier de los pobladores que en llo lugar non morar o lo leyxar fasta un anno complido el obispo desa eglisia de Sant Salvador de Çamora tomele ela casa et el heredamiento senon se el poblador dexar la vila por fame o por omezio.” y 17: “Et se por alguna cosas destas ela vila dexar et a la vila venier fasta tres annos recombe su casa et su heredamiento pagando ante al obispo todos sous fueros."

48 MARTÍN RODRÍGUEZ, J. L.: Amor, cuestión de señorío y otros estudios, Zamora, 1993. 
BARRIOS GARCÍA, A.: Estructuras agrarias y de poder en Castilla: El ejemplo de Ávila (1085-1320), Salamanca, 1983-1984.

CIMINO, C.: Diferenciación social campesina y señorío episcopal. Zamora, siglos XIXIII. UNLP. 2009.

MARTÍN RODRÍGUEZ, J. L.: Amor, cuestión de señorío y otros estudios, Zamora, 1993.

MARTÍNEZ MORO, J.: La tierra en la comunidad de Segovia. Un proyecto señorial urbano (1088-1500), Valladolid, 1985.

MARTÍNEZ SOPENA, P.: La Tierra de Campos Occidental. Poblamiento, poder y comunidad del siglo X al XIII, Valladolid, 1985.

MONSALVO ANTÓN, J. M.: El sistema político concejil. El ejemplo del señorío medieval de Alba de Tormes y su concejo de villa y tierra, Salamanca, 1988.

MíNGUEZ FERNÁNDEZ, J. M.: "Feudalismo y concejos. Aproximación metodológica al análisis de las relaciones sociales en los concejos medievales castellano-leoneses", En: En la España Medieval, III, Madrid, 1982.

MONSALVO ANTÓN, J. M.: “Transformaciones sociales y relaciones de poder en los concejos de frontera, siglos XI-XIII. Aldeanos, vecinos y caballeros ante las instituciones municipales." En: Relaciones de poder, de producción y parentesco en la Edad Media y Moderna. Reyna Pastor (Comp.), CSIC, Madrid, 1990.

PASTOR, R. et al: Transacciones sin mercado: instituciones, propiedad y redes sociales en la Galicia monástica. 1200-1300, CSIC, Madrid, 1999.

RODRÍGUEZ FERNÁNDEZ, J.: Los fueros locales de la provincia de Zamora. Junta de Castilla y León. 1990.

RODRÍGUEZ LÓPEZ, A. y PASTOR, R.: "Reciprocidades, intercambio y jerarquía en las comunidades medievales.” En: Hispania, LX / 1, N²04. 2000.

SÁNCHEZ RODRÍGUEZ, M.: Tumbo Blanco de Zamora, Salamanca, 1985.

SÁNCHEZ RODRÍGUEZ, M.: Fueros y posturas de Zamora (Tumbos Blanco y Negro), Salamanca, 1987.

VASSALLO, R.: Estructura y dinámica del dominio de Santo Toribio de Liébana (siglos XIII-XVI), Salamanca, 2003.

VILLAR GARCÍA, L. M.: La Extremadura castellano-leonesa. Guerreros, clérigos y campesinos (711-1252), Junta de Castilla y León, 1986. 